\title{
Um estudo sobre o posicionamento social e ambiental em indústrias do setor metal-mecânico da região noroeste do estado do Rio Grande do Sul
}

\author{
Juliana Siqueira \\ E-mail:sjuli@ibest.com.br \\ Eusélia Paveglio Vieira \\ E-mail:euselia@unijui.edu.br \\ Clóvis Antônio Kronbauer \\ E-mail: clovisk@unisinos.br
}

\section{RESUMO}

As organizações empresariais interagem com o ambiente e a sociedade de forma completa, na medida em que, com base na Teoria dos Sistemas, a empresa é considerada um sistema aberto e dinâmico, devido a sua interação com a sociedade e com o ambiente em que está inserida. E, essa interação influencia as pessoas, contribui para o aumento nos seus padrões de vida e também no desenvolvimento da sociedade como um todo. Dentro dessa ótica, objetivou-se com esse estudo descrever o posicionamento social e ambiental adotado nas organizações. Para sua consecução, desenvolveu-se um breve referencial teórico cobrindo os temas: organização e seu ambiente, sustentabilidade organizacional e ações sociais empresariais, e realizou-se uma pesquisa exploratória com a utilização de entrevistas realizadas com os gestores administrativos de três indústrias de grande porte do setor metal-mecânico sediadas na Região Noroeste do Estado do Rio Grande do Sul. Os resultados apontam para a incorporação da gestão do meio ambiente como parte do negócio empresarial nas empresas pesquisadas, bem como revelam um comportamento social que pode ser considerado como eticamente responsável por parte destas.

\section{INTRODUÇÃO}

As empresas privadas, além de contribuir com o crescimento econômico da sua região de inserção e micro-regiões vizinhas, também precisam contribuir com o desenvolvimento social, participando e colaborando com as ações sociais e com os anseios da comunidade local para que, dessa forma, tenham efetiva participação no desenvolvimento regional, sem deixar de lado as ações de gestão ambiental, com vistas à sustentabilidade desse desenvolvimento. 
Um estudo sobre o posicionamento social e ambiental em indústrias do setor metal-mecânico da região noroeste do estado do Rio Grande do Sul Juliana Siqueira, Eusélia Paveglio Vieira, Clóvis Antônio Kronbauer

O desenvolvimento regional, segundo Boisier (1996 apud DALLABRIDA, 2000, p. 27), pode ser compreendido como "um processo localizado de mudança social sustentada que tem como finalidade última o progresso permanente da região, da comunidade regional como um todo e de cada indivíduo residente nela". Ressalta-se, contudo, que o conceito de progresso, no contexto desta citação, não tem a conotação usual de "crescimento econômico a qualquer preço" e, sim, de melhoria, avanço ou evolução.

A definição de desenvolvimento no contexto deste estudo, é de "um processo de transformação econômica, política e social, através da qual o crescimento do padrão de vida da população tende a tornar-se automático e autônomo" (PEREIRA, 1983, p. 21). Trata-se de um processo social global, em que as estruturas econômicas, políticas e sociais de uma localidade sofrem contínuas e profundas transformações. Assim, devese compreender que a regra geral é que o desenvolvimento tenha como aspecto dominante de seu processo a transformação econômica e como resultado, por excelência, o crescimento do padrão de vida da população do local onde ocorre o desenvolvimento, ou seja, as empresas devem incorporar como parte do negócio os componentes social e ambiental.

Visando explorar essa temática no âmbito empresarial, optou-se realizar uma pesquisa em três indústrias de grande porte do setor metal-mecânico e que são muito representativas na economia da região Noroeste do Estado do Rio Grande do Sul, terceiro pólo metal-mecânico do Estado, segundo dados obtidos no site Panorama Econômico do Rio Grande do Sul (março/2004).

Dessa forma, definiu-se como objetivo do estudo, descrever o posicionamento dos gestores da área administrativa dessas indústrias no que concerne às ações desenvolvidas nas mesmas nos âmbitos social e ambiental.

Para tanto, o estudo contempla: um breve referencial teórico seguido dos procedimentos metodológicos adotados, da análise dos resultados e das considerações finais. 
Um estudo sobre o posicionamento social e ambiental em indústrias do setor metal-mecânico da região noroeste do estado do Rio Grande do Sul Juliana Siqueira, Eusélia Paveglio Vieira, Clóvis Antônio Kronbauer

\section{A ORGANIZAÇÃO E SEU AMBIENTE}

O ambiente geral da organização, conforme Bowditch e Buono (1997, p. 143), "se refere aos fatores, tendências e condições gerais que afetam a todas as organizações". Pode incluir as condições tecnológicas, os fatores sociais, as interações políticas, as condições econômicas, o sistema ecológico, as condições culturais, entre outros. Como esses fatores do ambiente geral podem ter impacto profundo sobre as organizações, é importante que as mesmas acompanhem as tendências e mudanças da sociedade.

Já, o ambiente específico "enfoca os fatores e as condições externas que tenham relevância imediata para a organização" (BOWDITCH; BUONO, 1997, p. 143). Geralmente, inclui os clientes, fornecedores, sindicatos, autoridades reguladoras, grupos de interesse público, associações de classe e outros públicos ou entidades relevantes da organização.

A distinção entre 0 ambiente geral e o específico depende das atividades centrais de uma dada organização e, embora sejam, às vezes, complexos e difíceis de se analisar, estes ambientes formam o que é chamado de textura causal dos ambientes da organização.

O ambiente real, por sua vez, "consiste nas entidades, objetos e condições que existem fora da empresa" (BOWDITCH; BUONO, 1997, p. 146). Cada organização tem um ambiente que é real, mensurável e externo à mesma, sendo que esta realidade pode impor algumas limitações ao modo de operar a empresa, enquanto que o ambiente percebido "reflete a interpretação subjetiva do ambiente real, que ocorre dentro da organização" (BOWDITCH; BUONO, 1997, p. 147). Assim, tanto o ambiente real como o percebido nas organizações são aspectos importantes da análise ambiental que deve ser explicitamente reconhecida nos processos de tomada de decisões.

\subsection{A sustentabilidade organizacional}

Apesar da crescente discussão teórica a respeito da relação positiva ou negativa entre as empresas e o meio ambiente, é impossível dimensionar o impacto dos grandes 
Um estudo sobre o posicionamento social e ambiental em indústrias do setor metal-mecânico da região noroeste do estado do Rio Grande do Sul Juliana Siqueira, Eusélia Paveglio Vieira, Clóvis Antônio Kronbauer

problemas ambientais causados pela forma da humanidade produzir e consumir. A alternativa, seguida atualmente por alguns empresários é incorporar o meio ambiente (ou a decisão pela proteção do meio ambiente) como parte do negócio empresarial, como uma ferramenta a mais para enfrentar a competitividade e se manter no mercado (RAMOS; FERNÁNDEZ, 2001).

Nesse contexto, o setor empresarial e, em particular, o industrial, se encontra em um duplo desafio: por um lado, precisa incorporar o componente meio ambiente na sua estratégia organizacional, realizando os investimentos necessários na investigação e no desenvolvimento de tecnologias limpas, na modificação de processos, na implantação de medidas corretivas, na gestão de resíduos etc, e, por outro lado, precisa posicionarse competitivamente em um mercado em nítida expansão.

É nesse sentido que na atualidade a gestão do meio ambiente, no âmbito da gestão empresarial, "começa a constituir-se num fator crucial que influencia decisivamente, tanto na imagem da empresa, quanto na qualidade do produto, no seu custo, sua comercialização e, definitivamente, na competitividade" (RAMOS; FERNÁNDEZ, 2001, p. 2). Assim, o caminho a ser trilhado pelas organizações que desejam sobreviver no tempo, ou seja, o caminho para a sustentabilidade organizacional, é incluir a ecologia em seus planejamentos e estratégias, o que implica em conceituar o meio ambiente desde seus aspectos naturais e artificiais, detectando os problemas atuais e futuros. "É mister ultrapassar as fronteiras setoriais e disciplinares, temporais e espaciais, para abordar a realidade com sua interdependência sistêmica, seus limites e suas complicações" (RAMOS; FERNÁNDEZ, 2001, p. 2).

Lentamente, a maior conscientização por parte dos consumidores e a pressão da opinião pública, parecem induzir o mundo dos negócios a adotar práticas sustentáveis em relação ao meio ambiente, com vistas a um desenvolvimento sustentável da humanidade. A exigência de conhecimento público, associado à sensibilização dos clientes e da população como um todo, tem levado muitas empresas a ampliar seu campo de observação sobre quem tem legítimos interesses em suas operações.

Nesse contexto, a relação das empresas com seus clientes também é algo 
Um estudo sobre o posicionamento social e ambiental em indústrias do setor metal-mecânico da região noroeste do estado do Rio Grande do Sul Juliana Siqueira, Eusélia Paveglio Vieira, Clóvis Antônio Kronbauer

essencial para a sobrevivência organizacional. Segundo Rust, Zeithaml e Lemon (2001, p. 16) "o valor no longo prazo de uma empresa é fortemente determinado pelo valor do relacionamento da empresa com seus clientes", assim quanto mais a empresa valorizar seus clientes, maior é a probabilidade de se manter no mercado.

O Valor do Cliente representa um modo inteiramente diferente de ver a lucratividade da organização, e, portanto, de ver os clientes, o marketing, o gerenciamento de informações e a estratégia. Ele se afasta da visão ultrapassada de examinar somente a lucratividade do produto ou o Valor da Marca e reconhece que os clientes são o centro dos negócios de qualquer empresa (RUST; ZEITHAML; LEMON, 2001, p. 65).

Além de estreitar a relação da empresa com seus clientes e valorizar sua imagem perante a sociedade, a adoção de conscientização ambiental empresarial, na parte de desenho dos produtos e seus processos, representa um dos métodos mais seguros para prevenir a contaminação ou dano ambiental. Os efeitos negativos da indústria sobre o meio ambiente não se limitam ao processo de fabricação, mas estendem-se as etapas prévias e/ou posteriores, onde a primeira é em relação às matérias-primas e à energia consumida, e a segunda relaciona-se com os produtos e desenhos gerados, pelo qual é necessário atender todo o ciclo de vida do produto.

Entretanto, salienta-se que "o êxito da transformação industrial por meio de novas tecnologias, de projetos inovadores e de melhores sistemas de gestão e controle dependerá em boa medida do reajuste global dos mercados" (RAMOS; FERNÁNDEZ, 2001 , p. 3). Isso significa que os preços atribuídos aos produtos precisam se modificar para refletir o verdadeiro custo ambiental da produção. Os mercados atuais oferecem poucos incentivos para o desenvolvimento de um comportamento ambiental responsável, especialmente, nos países subdesenvolvidos ou em desenvolvimento.

Considerando os elevados riscos ambientais derivados das práticas industriais contemporâneas, qualquer expansão significativa pode se considerar ecologicamente insustentável. Não obstante, "uma expansão desse tipo, onde se conduz um desenvolvimento global à medida que cresce a economia industrial, um país em via de desenvolvimento consegue suplantar suas necessidades e satisfazer expectativas cada vez mais exigentes" (RAMOS; FERNÁNDEZ, 2001, p. 4). 
Um estudo sobre o posicionamento social e ambiental em indústrias do setor metal-mecânico da região noroeste do estado do Rio Grande do Sul Juliana Siqueira, Eusélia Paveglio Vieira, Clóvis Antônio Kronbauer

Segundo a Organização das Nações Unidas (ONU, 1998), desenvolvimento sustentável é entendido como aquele em que as necessidades do presente são satisfeitas sem, contudo, comprometer a satisfação das necessidades das futuras gerações. Tal conceito envolve a manutenção ou, talvez, regeneração da produtividade dos ecossistemas, associada a um crescimento que possa ser mantido no longo prazo em termos ecológicos, econômicos e sociais.

A sustentabilidade organizacional e o desenvolvimento sustentável representam "um desafio para a humanidade, porque é um problema fundamentalmente de gestão" (RAMOS; FERNÁNDEZ, 2001, p. 5), pois o fator que mais tem limitado as medidas preventivas à degradação do meio ambiente no momento de conseguir a transação de práticas sustentáveis tecnológicas, são as práticas de gestão e controle. Portanto, sem uma mudança na cultura empresarial que prime por uma ética de preservação e por valores estratégicos de práticas sustentáveis, qualquer mudança que afete exclusivamente a parte tecnológica representará, normalmente, compromissos em curtíssimo prazo, ou seja, soluções imediatas, sem garantir o futuro ou a sustentabilidade organizacional.

\subsection{Ações sociais empresariais}

De acordo com Ashley (2002), o aumento da complexidade dos negócios economia globalizada, revolução tecnológica, proliferação de fontes de informações, entre outros - estaria impondo ao empresariado novas formas de realizar suas transações. A nova realidade estaria forçando as empresas a investir em outros atributos além do preço e qualidade: confiabilidade, serviço pós-venda, produtos ambientalmente corretos e relacionamento ético das empresas com seus consumidores, fornecedores, varejistas, além da valorização de práticas ligadas à segurança de seus funcionários e preservação do meio ambiente.

Da mesma forma, a prática de ações sociais, nos últimos anos, deixou de ser relacionada apenas a ações religiosas ou caritativas e passou a ser considerada como relevante para a dinâmica das organizações e da sociedade como um todo.

Nesse contexto, algumas expressões muito utilizadas em outros países passam 
Um estudo sobre o posicionamento social e ambiental em indústrias do setor metal-mecânico da região noroeste do estado do Rio Grande do Sul Juliana Siqueira, Eusélia Paveglio Vieira, Clóvis Antônio Kronbauer

a serem incorporadas no vocabulário das empresas brasileiras, mesmo que ainda não haja significados consensuais. É o caso de cidadania empresarial, expressão utilizada para caracterizar um conjunto de programas sociais adotados por empresas privadas. Os efeitos da globalização e da revolução tecnológica são alguns dos disseminadores dessas práticas no Brasil.

O conceito de cidadania empresarial em outros países está vinculado a práticas de filantropia e a noção de responsabilidade social. No Brasil, ainda não há um conceito definitivo para o termo, mas o que tem se observado na prática é que a cidadania empresarial está relacionada a programas estruturados de ação na comunidade, podendo ser através de uma fundação ou instituto.

Popularmente, o conceito tem sido tratado de forma bastante instrumental, como algo que pode trazer vantagem competitiva à organização frente à concorrência cada vez mais crescente. Seu aspecto mais enaltecido tem sido o de investimento na comunidade através de ações sociais ou projetos com recursos privados transferidos por empresas.

Martinelli (1997) propõe uma perspectiva evolucionista para as empresas, classificável em três estágios, quais sejam:

a) a empresa unicamente como um negócio: instrumento de interesses para o investidor, que em geral não é um empresário, e sim um "homem de negócios" com uma visão mais imediatista e financeira dos retornos de seu capital;

b) a empresa como organização social: aglutina os interesses de vários grupos de stakeholders - clientes, funcionários, fornecedores, sociedade (comunidade) e os próprios acionistas - e mantém com eles relações de interdependência. Estas relações podem estar refletidas em ações reativas (resolução de conflitos) ou pró-ativas, tendo para cada grupo de stakeholders uma política clara de atuação;

c) a empresa-cidadã: opera sob uma concepção estratégica e um compromisso ético resultando na satisfação das expectativas e respeito dos parceiros.

No estágio empresa-cidadã, segundo o autor, a empresa passa a agir na transformação do ambiente social, sem se ater unicamente aos resultados financeiros do balanço econômico, buscando avaliar a sua contribuição à sociedade e se 
Um estudo sobre o posicionamento social e ambiental em indústrias do setor metal-mecânico da região noroeste do estado do Rio Grande do Sul Juliana Siqueira, Eusélia Paveglio Vieira, Clóvis Antônio Kronbauer

posicionando de forma pró-ativa nas suas contribuições para os problemas sociais. A atuação como empresa-cidadã agregaria ao papel empresarial de agente econômico o papel de agente social, sem confundir os objetivos e instrumentos sociais com as práticas comerciais e com objetivos econômicos.

Martinelli (1997) argumenta, ainda, que a prática da cidadania empresarial poderia trazer à empresa promotora, ganhos substanciais, tais como: valor agregado à sua imagem; desenvolvimento de lideranças mais conscientes e socialmente responsáveis; melhoria do clima organizacional e da satisfação e motivação, decorrentes do aumento de auto-estima; e reconhecimento e orgulho pela participação em projetos sociais, entre outras vantagens.

A prática de ações sociais por empresas privadas está se tornando cada vez mais ativa e presente entre as grandes organizações, demonstrando um comportamento eticamente responsável e preocupado com os problemas sociais da comunidade, mesmo que essa prática possa vir a trazer benefícios à empresa, sejam eles financeiros ou não.

\section{PROCEDIMENTOS METODOLÓGICOS}

Do ponto de vista de sua natureza a pesquisa realizada pode ser enquadrada como aplicada (GIL, 1999), na medida em que se buscou conhecer a realidade empresarial no tocante a questão em estudo. Quanto à abordagem do problema a pesquisa é qualitativa. Nesse tipo de pesquisa utiliza-se a interpretação e a percepção dos fenômenos e a atribuição de significados para descrever os resultados (MINAYO, 2000). Quanto aos objetivos a pesquisa classifica-se como exploratória/descritiva, na medida em que se procurou conhecer e descrever o posicionamento dos dirigentes no que concerne à gestão social e ambiental nas respectivas organizações (GIL, 1999).

A amostra é composta por três indústrias de grande porte da região noroeste do Estado do RS definidas por critério de acessibilidade. A partir da definição da amostra, definiram-se os sujeitos da pesquisa, ou seja, os gestores que deveriam ser entrevistados. A escolha recaiu sobre os gestores administrativos aos quais, em geral, 
Um estudo sobre o posicionamento social e ambiental em indústrias do setor metal-mecânico da região noroeste do estado do Rio Grande do Sul Juliana Siqueira, Eusélia Paveglio Vieira, Clóvis Antônio Kronbauer

estão afetas de forma mais direta as questões relacionadas com as áreas social e ambiental.

A coleta de dados primários junto aos sujeitos da pesquisa deu-se através de entrevistas narrativas previamente agendadas, e mediante o uso de questionários semiestruturados. Os entrevistados foram estimulados a relatar acontecimentos importantes relacionados ao tema em estudo. A captação das informações nas entrevistas com os gestores de cada empresa deu-se pela forma manual-escrita, através de apontamentos em nota, e pela forma sonora, através do recurso de gravação devidamente permitido pelos entrevistados.

Já o tratamento dos dados coletados foi efetuado através de transcrição das percepções expressas nas entrevistas, considerando o fato de ser uma pesquisa com abordagem qualitativa do problema. Essas percepções foram objeto de análise e interpretação por parte do pesquisador.

Destaca-se que a pesquisa possui limitações, pois os resultados da análise desenvolvida junto à amostra escolhida (três indústrias do setor metal-mecânico) não podem ser estendidos às demais indústrias do setor, nem mesmo da região pesquisada.

\section{APRESENTAÇÃO E ANÁLISE DOS RESULTADOS}

\subsection{Caracterização das Organizações}

As organizações participantes do estudo podem ser caracterizadas como segue:

a) AGCO do Brasil: companhia de capital acionário privado norte-americano, que fabrica e distribui tratores, colheitadeiras, retro-escavadeiras, pás carregadeiras, tratores de esteira e pulverizadores. Possui 22 (vinte e duas) marcas, sendo que 13 (treze) se encontram no Brasil. No Rio Grande do Sul há duas fábricas: uma em Canoas (tratores) e outra em Santa Rosa (colheitadeiras). A fábrica de Santa Rosa foi adquirida em 1996 e conta com cerca de 1.300 empregados (dados de agosto/2004). Em 2003 chegou a produzir 250 máquinas/mês.

b) Kepler Weber: O Grupo Kepler Weber surgiu em 12 de maio de 1925, na cidade de Panambi, Rio Grande do Sul. Possui parques industriais em Panambi (RS), 
Um estudo sobre o posicionamento social e ambiental em indústrias do setor metal-mecânico da região noroeste do estado do Rio Grande do Sul Juliana Siqueira, Eusélia Paveglio Vieira, Clóvis Antônio Kronbauer

em Bauru (SP) e em Campo Grande (MS). Em 1966 teve seu controle acionário adquirido por instituições financeiras e de investimentos da América Latina. Desenvolve, fabrica e instala equipamentos destinados ao uso em unidades armazenadoras de cereais, indústrias de alimentos, instalações industriais e distribuição. Projeta e executa cerca de 500 instalações anuais e conta com 2.079 empregados (dados de setembro/2004).

c) John Deere do Brasil: foi fundada em 1837, nos Estados Unidos, e possui 32 fábricas localizadas em 12 países. É especializada em sistemas mecanizados agrícolas. Atua nas divisões: agrícola, equipamentos para construção, comercial, peças, motores e crédito. Em 1979 adquiriu 20\% da SLC de Horizontina (RS). Em 1996 introduziu a linha de tratores no Brasil, passando a deter 40\% da empresa e, em 1999, assumiu o controle total da mesma. Conta com 2.891 empregados na unidade de Horizontina (RS) e é responsável por $60 \%$ do total das exportações brasileiras de colheitadeiras (dados de dezembro/2004).

\subsection{Análise do Posicionamento Ambiental}

Frente à questão de relação positiva ou negativa entre as empresas e o meio ambiente, e o impacto da produtividade desenfreada sem se preocupar com os problemas ambientais, a alternativa seguida, atualmente, por alguns empresários é incorporar o meio ambiente como parte do negócio empresarial. A gestão ambiental passa a ser compreendida como uma ferramenta a mais para enfrentar a competitividade e buscar a sobrevivência empresarial.

Conforme foi referido na revisão de literatura, a gestão do meio ambiente, no âmbito da gestão empresarial, começa a constituir-se num fator decisivo que influencia tanto na imagem da empresa, quanto na qualidade do produto, no seu custo, sua comercialização e, definitivamente, na competitividade. Assim, entende-se que o caminho para as empresas alcançarem a sustentabilidade organizacional é considerar nos seus planejamentos e estratégias a questão ecológica, o que implica em compreender o meio ambiente desde seus aspectos naturais e artificiais, detectando os problemas atuais e futuros. 
Um estudo sobre o posicionamento social e ambiental em indústrias do setor metal-mecânico da região noroeste do estado do Rio Grande do Sul Juliana Siqueira, Eusélia Paveglio Vieira, Clóvis Antônio Kronbauer

Nesse contexto, procurou-se conhecer a percepção dos gestores administrativos, no que tange ao posicionamento ambiental das empresas e a forma como essa questão está sendo trabalhada.

a) Gestão e sustentabilidade ambiental

Foi formulada uma questão para saber se a gestão ambiental faz parte do negócio empresarial e de que forma a empresa posiciona-se frente à questão da sustentabilidade ambiental.

A AGCO incorporou a gestão ambiental como parte do negócio empresarial desde 1996, na fábrica de Santa Rosa/RS, porque esta foi uma condição imposta pela matriz para a aquisição dessa unidade industrial na época. A questão da sustentabilidade ambiental é vista e entendida com muita seriedade, segundo o gestor administrativo, pois além do respeito pela natureza, a empresa é totalmente consciente e age para não danificar ou prejudicar o meio ambiente. Para tanto, são tomadas certas atitudes como: todo o lixo gerado pela empresa é reciclado, há tratamento da água, a pintura dos produtos é feita com tinta em pó para não deixar resíduos no ar, entre outras.

A Kepler Weber passou a incorporar a gestão ambiental como parte do negócio empresarial mais fortemente a partir de 2002, quando foram instaladas duas estações de tratamento de efluentes, ou seja, tratamento da água, fumaça e resíduos químicos e biológicos da fábrica, considerando que, até 2002, a empresa cumpria apenas as exigências governamentais. Já em relação à sustentabilidade ambiental, o gestor administrativo compreende que a empresa trabalha para que haja preservação do meio ambiente, atendendo as exigências ambientais internacionais e antecipando-se às exigências do governo brasileiro, tanto em termos de equipamentos quanto em termos de processos da fábrica, procurando eliminar cada vez mais os ruídos, resíduos químicos e biológicos e a poluição do ar.

No caso da John Deere, a gestão ambiental já faz parte do negócio empresarial a bastante tempo, mas a partir de 2004 é que a empresa passou a ser certificada pelo SGA e está sendo auditada periodicamente para a manutenção do certificado. Quanto a sustentabilidade ambiental, o gestor administrativo esclarece que a empresa está 
Um estudo sobre o posicionamento social e ambiental em indústrias do setor metal-mecânico da região noroeste do estado do Rio Grande do Sul Juliana Siqueira, Eusélia Paveglio Vieira, Clóvis Antônio Kronbauer

comprometida em conduzir seus negócios no mundo todo de forma a proteger as pessoas e a preservar o meio ambiente. Procura-se fazer com que o design dos produtos e a conduta das operações da empresa eliminem riscos para os clientes, funcionários, vizinhos e comunidade onde está inserida, além de cumprir com o propósito de todos os padrões do mercado local, leis e regulamentações aplicáveis.

b) Gestão ambiental considerada como estratégia competitiva

Foi proposta uma questão que procurava saber se a gestão ambiental é considerada uma estratégia frente ao contexto de competitividade do mercado.

O gestor da AGCO assinalou que a empresa não tira muito proveito da gestão ambiental tida como estratégia frente à competitividade, isto é, a gestão do meio ambiente ainda não se tornou um instrumento de marketing. Na visão do gestor, o cliente ainda não está preparado para valorizar essa posição ou esse investimento, tendo outras prioridades como, por exemplo, a qualidade e o rendimento do produto.

Para o gestor administrativo da Kepler Weber, a gestão do meio ambiente está sendo usada estrategicamente, tendo em vista os prêmios recebidos e as certificações alcançadas nos últimos anos. Mas, a empresa procura sempre evidenciar que essa questão é trabalhada com seriedade e não usada unicamente como meio de publicidade e propaganda.

$\mathrm{Na}$ John Deere, a gestão ambiental é considerada uma estratégia frente ao contexto de competitividade do mercado, pois, segundo o gestor administrativo, há uma tendência muito forte do consumidor, principalmente, de países mais desenvolvidos, de não comprar produtos de empresas que não agem em favor do meio ambiente e que não possuem o selo verde.

A concepção dos gestores administrativos quanto ao posicionamento ambiental está sintetizada no quadro1, a seguir. 
Um estudo sobre o posicionamento social e ambiental em indústrias do setor metal-mecânico da região noroeste do estado do Rio Grande do Sul

Juliana Siqueira, Eusélia Paveglio Vieira, Clóvis Antônio Kronbauer

\begin{tabular}{|c|c|c|}
\hline \multicolumn{3}{|c|}{ Gestão ambiental como parte do negócio } \\
\hline AGCO & Kepler Weber & John Deere \\
\hline $\begin{array}{l}\text { Sim. Desde 1996, quando a } \\
\text { unidade de Santa Rosa foi } \\
\text { adquirida pela empresa. }\end{array}$ & $\begin{array}{l}\text { Sim. Principalmente a partir de } \\
2002 \text {, quando instalou duas } \\
\text { estações de tratamento de } \\
\text { efluentes. }\end{array}$ & $\begin{array}{l}\text { Sim, há bastante tempo, mas a } \\
\text { partir de } 2004 \text { é que a empresa } \\
\text { passou a ser certificada pela } \\
\text { SGA e está sendo auditada } \\
\text { periodicamente para a manu- } \\
\text { tenção do certificado. }\end{array}$ \\
\hline \multicolumn{3}{|c|}{ Posicionamento frente a sustentabilidade ambiental } \\
\hline AGCO & Kepler Weber & John Deere \\
\hline $\begin{array}{l}\text { Há total consciência e se age } \\
\text { para não danificar ou pre- } \\
\text { judicar o meio ambiente. } \\
\text { Tomam-se atitudes como: } \\
\text { todo o lixo gerado na empresa } \\
\text { é reciclado; há tratamento } \\
\text { para a água; a pintura dos } \\
\text { produtos é feita com tinta em } \\
\text { pó para não deixar resíduos } \\
\text { no ar, etc. }\end{array}$ & $\begin{array}{l}\text { Trabalha-se para que haja pre- } \\
\text { servação ambiental, atendendo } \\
\text { exigências ambientais interna- } \\
\text { cionais e antecipando-se às } \\
\text { exigências do governo, em ter- } \\
\text { mos de equipamentos e } \\
\text { proces-sos da fábrica, } \\
\text { procurando eli-minar ruídos, } \\
\text { resíduos quími-cos/biológicos e } \\
\text { poluição do ar. }\end{array}$ & $\begin{array}{l}\text { Há um compromisso em } \\
\text { conduzir os negócios no mundo } \\
\text { todo, de forma a proteger as } \\
\text { pessoas e a preservar o meio } \\
\text { ambiente. Procura-se fazer com } \\
\text { que o design dos produtos e a } \\
\text { conduta das operações } \\
\text { eliminem riscos para os } \\
\text { clientes, funcionários, vizinhos } \\
\text { e comunidade, além de cumprir } \\
\text { com o propósito de todos os } \\
\text { padrões do mercado local e leis } \\
\text { de regulamentações aplicáveis. }\end{array}$ \\
\hline \multicolumn{3}{|c|}{ Gestão ambiental considerada como estratégia frente ao contexto de competitividade } \\
\hline AGCO & Kepler & John Deere \\
\hline $\begin{array}{l}\text { Não se tira proveito como } \\
\text { estratégia frente à competi- } \\
\text { tividade; a gestão ambiental } \\
\text { ainda não se tornou um } \\
\text { instrumento de marketing. }\end{array}$ & $\begin{array}{l}\text { Está sendo usada estratégica- } \\
\text { mente, tendo em vista os prê- } \\
\text { mios e certificações } \\
\text { alcançadas. Essa questão é } \\
\text { trabalhada com seriedade, não } \\
\text { sendo únicamente meio de } \\
\text { publicidade. }\end{array}$ & $\begin{array}{l}\text { É considerada uma estratégia } \\
\text { frente ao contexto de compe- } \\
\text { titividade do mercado, pois há } \\
\text { uma tendência muito forte do } \\
\text { consumidor, principalmente de } \\
\text { países mais desenvolvidos, de } \\
\text { não comprar produtos de em- } \\
\text { presas que não agem a favor } \\
\text { do meio ambiente e que não } \\
\text { pos-suam o selo verde. }\end{array}$ \\
\hline
\end{tabular}

Quadro 1 - Posicionamento ambiental nas empresas

Diante da percepção dos gestores administrativos, verificou-se que as três empresas pesquisadas já incorporaram a gestão do meio ambiente como parte do negócio empresarial, procurando ressaltar o que estão fazendo em termos de proteção da natureza. Essa atitude não partiu de uma exigência do governo brasileiro, mas de imposição de governos estrangeiros e do mercado globalizado.

Outro ponto que pode ter contribuído para a adoção da gestão ambiental é a nova postura do mercado consumidor e da sociedade frente à proteção e preservação do meio ambiente. Além de atender às exigências legais, as empresas também 
Um estudo sobre o posicionamento social e ambiental em indústrias do setor metal-mecânico da região noroeste do estado do Rio Grande do Sul Juliana Siqueira, Eusélia Paveglio Vieira, Clóvis Antônio Kronbauer

atendem as exigências dos consumidores que passaram a ser mais exigentes e críticos, principalmente, os de mercados estrangeiros.

Constata-se, também, a partir da percepção dos gestores, que a saída comum encontrada pelas empresas é alocar os custos com a gestão ambiental nos custos indiretos de fabricação, e os grandes investimentos em mudanças de processos com tecnologias limpas estão sendo alocados na conta investimentos, já que não podem ser diretamente alocados aos produtos.

Na visão de Ramos e Fernández (2001), o êxito de uma transformação industrial por meio de novas tecnologias, de projetos inovadores e de melhores sistemas de gestão e controle, dependerá em grande parte do reajuste global dos mercados, isso porque os preços fixados aos produtos precisam se modificar para refletir o verdadeiro custo ambiental da produção.

No entanto, mesmo que as empresas não estejam acoplando aos preços de venda os custos com investimento em tecnologias limpas e gestão ambiental, a decisão de incorporar o meio ambiente no negócio está sendo amplamente adotada com intuito de garantir a sustentabilidade organizacional. Este posicionamento é positivo para as empresas e para a sociedade como um todo, tendo em vista a preservação do meio ambiente.

Quanto à utilização da gestão ambiental como estratégia competitiva, verificouse que apenas os gestores da AGCO ainda não estão fazendo uso da gestão do meio ambiente como estratégia frente ao mercado, enquanto que os gestores da Kepler Weber e da John Deere já estão utilizando para se posicionar no mercado.

O uso da ferramenta de marketing para proteger ou melhorar o ambiente natural nas atividades comerciais é uma prática conhecida como "marketing verde". Trata-se de uma prática cada vez mais difundida entre as empresas que implantaram a gestão ambiental e que procuram divulgar os bons resultados alcançados com tecnologias limpas e produtos verdes, com intuito de conquistar clientes e consolidar a imagem organizacional. 
Um estudo sobre o posicionamento social e ambiental em indústrias do setor metal-mecânico da região noroeste do estado do Rio Grande do Sul Juliana Siqueira, Eusélia Paveglio Vieira, Clóvis Antônio Kronbauer

\subsection{Análise do Posicionamento Social}

As empresas, além de estarem frente ao desafio de incorporar o componente meio ambiente na sua estratégia organizacional, também estão inseridas no engajamento de seu meio de inserção em favor do desenvolvimento econômico, social e sustentável.

A prática de ações sociais, nos últimos anos, deixou de ser relacionada apenas a ações religiosas ou caritativas e passou a ser considerada como ponto relevante para a dinâmica das organizações e da sociedade como um todo.

Nesse contexto, procurou-se investigar o papel assumido pelas empresas diante do processo de desenvolvimento local e regional, considerando os aspectos econômicos, sociais e ambientais, e a forma como o mesmo impacta na gestão de custos de cada empresa.

a) O Papel das empresas diante do desenvolvimento local e regional

Formulou-se uma questão para conhecer o papel assumido nas empresas diante do processo de desenvolvimento local e regional, considerando os aspectos econômicos, sociais e ambientais.

Para o gestor da AGCO, em Santa Rosa/RS, procura-se atuar mais em nível de desenvolvimento local, colaborando com a comunidade e o município. Atualmente, a empresa gera cerca de $30 \%$ do movimento do ICMS do município. Procura terceirizar vários serviços, não apenas para benefício próprio, mas com o intuito de colaborar com 17 pequenas empresas (formadas por ex-colaboradores) de Santa Rosa e de cidades vizinhas, gerando cerca de 2000 empregos indiretos. Também é destinada certa quantia por ano, através de um percentual sobre o faturamento, para ajudar instituições sociais como orfanatos, asilos, escolas públicas, etc., cujo montante em 2003 foi de $R \$$ $90.000,00$.

A Kepler Weber, no âmbito social interno, conta com profissionais específicos assistentes sociais - para atuar diretamente com seus colaboradores, além de oferecer assistência médica e odontológica, planos de educação superior, cobrindo tanto graduação quanto especialização. Em relação a parte social externa, conforme o gestor administrativo, há uma previsão orçamentária de doações sob a incumbência da 
Um estudo sobre o posicionamento social e ambiental em indústrias do setor metal-mecânico da região noroeste do estado do Rio Grande do Sul Juliana Siqueira, Eusélia Paveglio Vieira, Clóvis Antônio Kronbauer

Gestão de Responsabilidade Social - uma área dentro da área de $\mathrm{RH}$; e os setores priorizados são o setor educacional (escolas públicas) e o setor de moradia (construção de casas populares).

No caso da John Deere, o gestor administrativo assinalou que para que a empresa possa desempenhar com sucesso sua função na sociedade como um fornecedor de produtos e serviços, e gerador de empregos, existem várias partes interessadas que precisam confiar na integridade, competência e cidadania de seus dirigentes. Por isso, em primeiro plano para a John Deere estão os clientes, funcionários, investidores, concessionárias, outros parceiros de negócios e fornecedores. No entanto, estão também incluídas as comunidades onde a empresa está inserida, os governos e outras instituições sociais com as quais procura-se engajar na busca do bem-estar social, através de contribuições financeiras e participações em eventos e campanhas beneficentes.

A concepção dos gestores administrativos quanto ao posicionamento social nas empresas está sintetizada no quadro 2, a seguir. 
Um estudo sobre o posicionamento social e ambiental em indústrias do setor metal-mecânico da região noroeste do estado do Rio Grande do Sul

Juliana Siqueira, Eusélia Paveglio Vieira, Clóvis Antônio Kronbauer

\begin{tabular}{|c|c|c|}
\hline \multicolumn{3}{|c|}{ Papel assumido na empresa diante do processo de desenvolvimento local e regional } \\
\hline AGCO & Kepler Weber & John Deere \\
\hline $\begin{array}{l}\text { Procura-se atuar mais em } \\
\text { nível de desenvolvimento } \\
\text { local, colaborando com a } \\
\text { comunidade e o município. } \\
\text { Terceirizam-se rer vários } \\
\text { serviços, com vistas a ajudar } \\
\text { cerca de } 17 \text { pequenas } \\
\text { empresas de Santa Rosa e de } \\
\text { cidades vizinhas, gerando } \\
\text { cerca de } 2000 \text { empregos } \\
\text { indiretos. E, destina-se certa } \\
\text { quantia por ano, através de } \\
\text { um percentual sobre o } \\
\text { faturamento (2003: mais de } \\
\text { R } \$ 0.000,00) \text { para ajudar } \\
\text { instituições como orfanatos, } \\
\text { asilos, escolas públicas, etc. }\end{array}$ & $\begin{array}{l}\text { No âmbito social interno, conta- } \\
\text { se com profissionais } \\
\text { específicos para atuar } \\
\text { diretamente com seus } \\
\text { colaboradores, além da assis- } \\
\text { tência médica e odontológica, } \\
\text { planos de educação superior, } \\
\text { cobrindo graduações e espe- } \\
\text { cializações. Para a parte social } \\
\text { externa, há uma previsão } \\
\text { orçamentária de doações sob a } \\
\text { incumbência da Gestão de } \\
\text { Responsabilidade Social; os } \\
\text { setores priorizados são: o } \\
\text { educacional (escolas públicas) } \\
\text { e o de moradia (construção de } \\
\text { casas populares). }\end{array}$ & $\begin{array}{l}\text { Para desempenhar } r \text { com } \\
\text { sucesso sua função na } \\
\text { sociedade como uma } \\
\text { fornecedora de produtos, } \\
\text { serviços e geradora de empre- } \\
\text { gos, existem pr partes } \\
\text { interessadas que precisam } \\
\text { confiar na inte-gridade, } \\
\text { competência e cidada-nia da } \\
\text { empresa. Por isso, } \\
\text { preeminentes estão os clientes, } \\
\text { funcionários, investidores, con- } \\
\text { cessionárias, outros parceiros } \\
\text { de negócios e fornecedores. } \\
\text { Também estão incluídas as } \\
\text { comunidades, os governos e } \\
\text { outras instituições sociais a } \\
\text { quem a empresa procura enga- } \\
\text { jar-se na busca do bem estar } \\
\text { social, através de contribuições } \\
\text { financeiras e participações em } \\
\text { eventos e campanhas benefi- } \\
\text { centes. }\end{array}$ \\
\hline
\end{tabular}

Quadro 2 - Posicionamento social nas empresas

Como se observa, cada empresa procura atuar socialmente junto à comunidade em que está inserida, seja gerando empregos diretos e indiretos, ou praticando ações sociais em projetos beneficentes. Essas atitudes demonstram um comportamento eticamente responsável e preocupado com os problemas sociais, mesmo que essa prática possa vir a trazer benefícios à empresa, sejam eles financeiros ou não.

A forma como as empresas procuram administrar as ações sociais no gerenciamento de custos pode variar, mas a sua participação na implementação de estratégias voltadas para o desenvolvimento regional tem o mesmo princípio: alavancar e consolidar o processo de desenvolvimento da sua região, além de colaborar para o bem-estar social.

Percebe-se que há uma relação social positiva entre as empresas pesquisadas e a região em que estão inseridas. O investimento em projetos sociais, a geração de empregos diretos e indiretos e o fortalecimento da economia dos municípios, demonstra que as empresas estão contribuindo para o crescimento econômico da sua região e 
Um estudo sobre o posicionamento social e ambiental em indústrias do setor metal-mecânico da região noroeste do estado do Rio Grande do Sul Juliana Siqueira, Eusélia Paveglio Vieira, Clóvis Antônio Kronbauer

micro-regiões vizinhas e, também, estão colaborando com o desenvolvimento social, participando de ações sociais e atendendo anseios da comunidade local, sem deixar de lado as ações de gestão ambiental, com vistas a sustentabilidade deste desenvolvimento.

\section{CONSIDERAÇÕES FINAIS}

A pesquisa exploratória realizada permitiu constatar que em relação ao posicionamento ambiental, as três empresas pesquisadas já incorporaram a gestão do meio ambiente como parte do negócio empresarial. Essa atitude não partiu, necessariamente, de exigências do governo brasileiro, mas de imposição de governos estrangeiros e do mercado globalizado. Ressalta-se, também, que, além de atender às exigências legais, as empresas estão atendendo às exigências dos consumidores que passaram a ser mais exigentes e críticos, principalmente, os de mercados estrangeiros.

No que se refere ao posicionamento social, percebeu-se que cada empresa está atuando junto à comunidade em que está inserida, seja através da geração de empregos diretos e indiretos, ou da prática de ações sociais em projetos beneficentes, permitindo considerar que há uma relação social positiva entre as empresas e a região em que estão inseridas, na medida em que contribuem com o crescimento econômico da sua região e micro-regiões vizinhas e, também, colaboram com o desenvolvimento social, participando de ações sociais e dos anseios da comunidade local, sem deixar de lado as ações de gestão ambiental, com vistas a dar sustentabilidade a este desenvolvimento.

\section{REFERÊNCIAS}

ASHLEY, Patrícia A. A responsabilidade social nos negócios: um conceito em construção. In: . Ética e responsabilidade social nos negócios. São Paulo: Saraiva, 2002.

BOWDITCH, James L.; BUONO, Anthony F. Elementos de comportamento organizacional. Tradução de José Henrique Lamendorf. São Paulo: Thomson Pioneira, 1997. p. 142-165. 
Um estudo sobre o posicionamento social e ambiental em indústrias do setor metal-mecânico da região noroeste do estado do Rio Grande do Sul Juliana Siqueira, Eusélia Paveglio Vieira, Clóvis Antônio Kronbauer

DALLABRIDA, Valdir Roque. O desenvolvimento regional: a necessidade de novos paradigmas. Ijuí: Ed. Unijui, 2000.

GIL, Antonio Carlos. Métodos e técnicas de pesquisa social. São Paulo: Atlas, 1999.

MARTINELLI, Antônio Carlos. Empresa-cidadã: uma visão inovadora para uma ação transformadora. In: IOSCHPE, Evelyn B. Terceiro setor: desenvolvimento social sustentado. São Paulo: Paz e Terra, 1997.

ORGANIZAÇÃO DAS NAÇÕES UNIDAS (ONU). Comissão Mundial sobre o Desenvolvimento. Nosso futuro comum. Relatório Bruthland. São Paulo: Fundação Getúlio Vargas, 1998.

PEREIRA, Luiz C Bresser. Desenvolvimento e crise no Brasil. 13.ed. São Paulo: Brasiliense, 1983.

RAMOS, Aldo Guzmán; FERNÁNDEZ, Guillermina. La gestion ambiental empresarial sustentable - realidad o utopia? Espanha: INEC, 2001. Artigo de divulgação científica.

RIO GRANDE DO SUL. Panorama econômico do Rio Grande do Sul. Disponível em: <http://www.ccirs.com.br/dados_rs.htm> Acesso em 28/03/2004.

RUST, Roland T.; ZEITHAML, Valarie; LEMON, Katherine N. O valor do cliente. Tradução Nivaldo Montingelli Jr. Porto Alegre: Bookman, 2001. 